\title{
EFEITO RESIDUAL DE SÓLIDOS ORGÂNICOS UTILIZANDO CASCA DE AMENDOIM E DOSES CRESCENTES DE AMÔNIA NO CULTIVO DA MAMONA BRS GABRIELA
}

\section{EFECTO DE SÓLIDOS ORGÁNICOS RESIDUAL UTILIZANDO CACAHUETE CORTEZA Y DOSIS CULTIVO DE AMONIACO EN CASTOR BRS GABRIELA}

\section{RESIDUAL \\ EFFECTOFORGANICSOLIDUSINGPEANUTSHELLANDINCREASINGDOSESOF AMMONIAINFARMINGCASTOR BRSGABRIELA}

\author{
Fabiana Xavier $\operatorname{COSTA}^{1}$ \\ Luis Alberto Silva ALBUQUERQUE ${ }^{2}$ \\ Jair Clério ARAÚJO \\ Leonardo Pereira SILVA ${ }^{4}$ \\ José Sebastião MELO FILHO
}

RESUMO: Objetivou-se com este trabalho, estudar o crescimento e produção da mamona BRS Gabriela, avaliando como matéria orgânica o efeito residual da casca de amendoim natural e moída e níveis crescente de adubação nitrogenada. Um experimento foi desenvolvido em condições de pleno sol nas dependências da Universidade Estadual da Paraíba, Campus IV. Foi utilizado o delineamento bloco casualisado, usando dosagens de nitrogênio $\left(0 ; 30 ; 60 ; 90 \mathrm{~kg} \mathrm{ha}^{-1}\right)$, e duas formas de casca de amendoim (natural ou moída), adotando-se o esquema fatorial $2 \times 4$, resultando em 8 tratamentos com 4 repetições ,totalizando 32 parcelas experimentais. Foram analisados a altura da planta, diâmetro do caule, número de ramificações, número de nós, numero de folhas, área foliar, comprimento da raiz, numero de racemos, numero de frutos por planta, numero de sementes por planta. Pelos resultados, pode-se concluir, em geral, a utilização da casca moída no substrato sobressaiua casca natural no desenvolvimento da mamoneira, A mamoneira responde positivamente a doses superiores a $90 \mathrm{~kg} / \mathrm{ha}$ de nitrogênio e a casca moída de amendoim apresentou melhor desempenho quanto ao crescimento e produção em comparação a caca natural.

Palavras- chave: Adubação orgânica, adubação mineral, nordeste brasileiro

\footnotetext{
${ }^{1}$ Prof. Dra. do Departamento de Agrárias e Exatas da Universidade Estadual da Paraíba - UEPB/Campus IV. Bióloga, Doutorado em Recursos Naturais. CEP 58884-000 - Catolé do Rocha - Paraíba - Brasil. fabyxavierster@gmail.com

${ }^{2}$ Ciências Agrárias. Departamento de Ciências Agrárias e Exatas. Universidade Estadual da Paraíba.

${ }^{3}$ Ciências Agrárias. Departamento de Ciências Agrárias e Exatas. Universidade Estadual da Paraíba.

${ }^{4}$ Ciências Agrárias. Departamento de Ciências Agrárias e Exatas. Universidade Estadual da Paraíba.

${ }^{5}$ Mestre em Sistemas Agroindustriais, Universidade Federal de Campina Grande - UFCG - Pombal- Paraíba Brasil. josesebastiaouepb@yahoo.com.br
} 
RESUMEN: El objetivo de este trabajofueestudiarelcrecimiento y rendimiento de ricino BRS Gabriela, laevaluación de lamateriaorgánica como elefecto residual de los cascos de maní natural y suelo y el aumento de los niveles de fertilización nitrogenada. Se realizóun experimento en condiciones de pleno sol enlasinstalaciones de laUniversidaddel Estado de Paraíba, Campus IV. Se utilizóeldiseño de bloques al azar, utilizando dosis de nitrógeno (0, 30, 60, $90 \mathrm{~kg}$ ha-1), y dos tipos de cáscara de maní (terreno natural o), que adoptaneldiseñofactorial $2 \times 4$, lo que resulta en 8 tratamientoscon 4 repeticiones, conun total de 32 parcelas experimentales. Analizamosla altura de planta, diámetrodeltallo, número de ramas, número de nodos, número de hojas, área foliar, longitud de laraíz, número de racimos, número de frutos por planta, número de semillas por planta. De los resultados, se puede concluir, en general, el uso de sustrato de concha triturada sobresalidoenlacorteza natural eneldesarrollo de semillas de ricinoUn grano de ricino responde positivamente a dosis superiores a $90 \mathrm{~kg} \mathrm{/} \mathrm{ha} \mathrm{de} \mathrm{nitrógeno} \mathrm{y} \mathrm{cáscaras} \mathrm{de} \mathrm{cacahuetes} \mathrm{de}$ tierramostróunmejorrendimientoenrelaciónconelcrecimiento rendimientoencomparaciónconel caca natural.

Palabras clave: abono orgánico, fertilizantes minerales, elnoreste de brasil

\begin{abstract}
The objective of this work was to study the growth and yield of castor BRS Gabriela, evaluating organic matter as the residual effect of natural peanut hulls and ground and increasing levels of nitrogen fertilization. An experiment was conducted in sunny conditions on the premises of the State University of Paraíba, Campus IV. The randomized block design was used, using doses of nitrogen $(0,30,60,90 \mathrm{~kg}$ ha -1$)$, and two forms of peanut butter (natural or ground ) shell, adopting the $2 \times 4$ factorial design , resulting in 8 treatments with 4 replicates, totaling 32 experimental plots. We analyzed plant height, stem diameter, number of branches, number of nodes, number of leaves, leaf area , root length, number of racemes, number of fruits per plant, number of seeds per plant. From the results, we can conclude, in general, the use of ground bark substrate excelling in the natural bark in the development of castor bean, Castor responds positively to greater than $90 \mathrm{~kg} / \mathrm{ha}$ of nitrogen doses and ground peanut hulls performed better as the growth and yield compared to peanut shell.
\end{abstract}

Keywords: Organic fertilization, mineral fertilizer, brazilian northeast

\title{
1-INTRODUÇÃO
}

A mamoneira é uma planta rústica, heliófila, resistente à seca, pertencente à família das Euforbiáceas, disseminada por diversas regiões do globo terrestre e cultivada comercialmente entre os paralelos $52^{\circ} \mathrm{N}$ e $40^{\circ} \mathrm{S}$ (COSTAet al., 2010a; LIMA et al., 2008).

A mamona (RicinuscommunisL.) se destaca por ser uma planta que se desenvolve em regiões tropicais e semiáridas, abrangendo áreas como as do Nordeste brasileiro. Pode ser 
plantada em sistema de consórcio e/ou rodízio com outras culturas como feijão, mandioca e milho, que servem à alimentação diária. O principal produto da mamona é o óleo de rícino, que é uma importante matéria-prima para a indústria química, com larga utilização na composição de inúmeros produtos como: tintas, vernizes, cosméticos, fluidos hidráulicos e plásticos. Entretanto, nos últimos anos com o despertar para energias renováveis como o biodiesel, o óleo de rícino começou a ser enxergado como meio produtivo para obtenção de combustível renovável.

Nesse contexto, de acordo com (COSTAet al., 2010b) a mamoneira possui bastante representatividade no cenário econômico e social, pois de suas sementes é extraído o óleo, principal produto utilizado na fabricação do biodiesel.

Sendo, assim, segundo (BELTRÃOet al, 2008) a mamona possui teor médio de óleo nas sementes principais recomendadas para cultivo. Seu óleo é especial: o único produzido pela natureza solúvel em álcool, o mais denso e viscoso de todos os óleos vegetais e animais que a natureza concebeu, possuindo propriedades singulares que o fazem o mais versátil de todos, com mais de 750 aplicações industriais e um dos melhores para produção de biocombustíveis, como o biodiesel.

Embora seja considerada uma planta de elevada resistência à seca, para produzir bem, a mamona necessita de pelo menos 16 nutrientes e aproximadamente $500 \mathrm{~mm}$ de chuva bem distribuída ao longo de seu ciclo (COSTAet al., 2009; BELTRÃO et al., 2008).

Embora tenha importância socioeconômica, a espécie conta com poucos cultivares melhorados para o Nordeste, mesmo com sua ampla variabilidade genética e que seu melhoramento na Região ocorra desde a década de 1960 (BAHIA et al., 2008).

Existem perspectivas para obtenção de cultivares que possam aumentar a produtividade do fruto (BAHIA et. al., 2008), e o teor de óleo dos grãos, permitindo a identificação de fontes de resistência às principais pragas e doenças da cultura, já que sua diversidade é ainda pouco explorada (CARVALHO, 2008).

A mamoneira (RicinuscommunisL.) é uma oleaginosa de valor socioeconômico elevado para as regiões produtoras e fonte de divisas para o país. Seus produtos e subprodutos são utilizados na indústria ou na agricultura, além de apresentar perspectivas de uso como fonte energética sob a forma de biodiesel (COSTAet al., 2011). Trata-se de uma das melhores opções para viabilizar o desenvolvimento sustentável, ao proporcionar emprego e renda principalmente para os pequenos produtores em tempos de instabilidade climática (CARVALHO, 2008). 
Foi utilizada nessa pesquisa a cultivar de mamona BRS Gabriela produzida pela Embrapa Algodão, Campina Grande, PB, na safra de 2012. Esta cultivar se destaca pela precocidade e produtividade, com características de porte pequeno, sendo seu ciclo curto, compreendendo em média 140 dias. Ela vem do cruzamento da BRS Nordestina com a BRS Paraguaçu, vindo de uma população segregante, apresentando frutos menores do que os dos pais, e sementes rajadas.

Neste contexto, objetivou-se com este trabalho estudar as características agronômicas da mamona BRS Gabriela, avaliando como matéria orgânica o efeito residual da casca de amendoim natural e moída utilizada em um experimento anterior com o girassol e adicionando-se doses crescentes de nitrogênio na forma de amônia (20\%) e doses fixas de fósforo na forma de superfosfato simples, no município de Catolé do Rocha - PB.

\section{2 - MATERIAIS E MÉTODOS}

O presente trabalho foi realizado na área experimental do Campus IV da Universidade Estadual da Paraíba, no município de Catolé do Rocha situado a $272 \mathrm{~m}$ de altitude, $6^{\circ} 20^{\prime} 38^{\prime \prime}$ S Latitude e $37^{\circ} 44^{\prime} 48^{\prime \prime}$ O Longitude, em regime de sequeiro.

A cultura utilizada foia mamona BRS Gabriela, produzida naEMBRAPA Algodão, em Campina Grande - PB, ciclo de 100 a 120 dias. Oriunda a partir de linhagens segregantese cruzamentos entre as cultivares BRS Nordestina e BRS Paraguaçu, com altura inferior aos parentais.

No Laboratório de Análises Químicas do Solo, do Departamento de Solos da UFCG de Campina Grande-PB, foram realizadas as análises química e física do substrato de solo antes do plantio do girassol, no experimento anterior (Tabelas 1 e 2). Os teores de macronutrientes foram determinados a partir das amostras de solo retiradas na profundidade de 0-20 cm do campo experimental da UEPB, Campus IV, Catolé do Rocha - PB.

Tabela 1. Característica química do solo que foi usado no experimento anterior com o girassol. UEPB. Catolé do Rocha - PB, 2013/2014. 


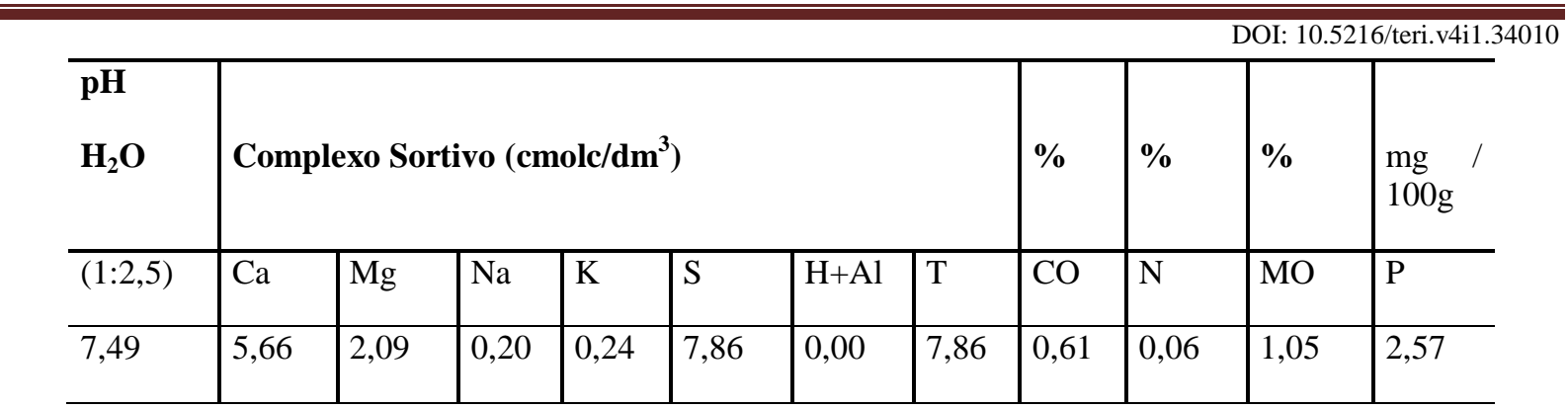

Análises realizadas no Laboratório de Solo da Universidade Federal de Campina Grande. Campina Grande, PB. 2012. MO = matéria orgânica. $\mathrm{S}=$ soma de bases trocáveis do solo, mais a acidez hidrolítica $(\mathrm{H}+\mathrm{Al})$, que no caso foi zero. $\mathrm{T}=\mathrm{S}+\mathrm{H}+$ Al. $\mathrm{CO}=$ carbono orgânico.

Tabela 2. Característica física do solo que foi usado no experimento anterior com o girassol. UEPB. Catolé do Rocha - PB, 2013/2014.

\begin{tabular}{|c|c|c|c|c|c|c|c|}
\hline \multicolumn{3}{|c|}{ Densidade - kg/dm ${ }^{3}$} & \multicolumn{4}{|c|}{ Granulometria - \% } & \multirow[b]{2}{*}{ Classificação Textural } \\
\hline Global & Real & $\begin{array}{l}\text { Porosidade } \\
\text { Total (\%) }\end{array}$ & $\begin{array}{l}\text { Areia } \\
\text { Grossa }\end{array}$ & $\begin{array}{l}\text { Areia } \\
\text { Fina }\end{array}$ & Silte & Argila & \\
\hline 1,02 & 2,67 & 61,90 & 54,60 & 43,90 & 23,00 & 22,40 & Franco Argilo Arenoso \\
\hline
\end{tabular}

Análises realizadas no Laboratório de Solo da Universidade Federal de Campina Grande. Campina Grande - PB, 2013.

As análises da casca de amendoim utilizadas no experimento anterior com o girassol foram feitas no Laboratório de Química da Embrapa Algodão (Tabela 3).

Tabela 3- Característica química da casca de amendoim que foi usado no experimento anterior com o girassol. UEPB. Catolé do Rocha - PB, 2013/2014.

\begin{tabular}{|c|c|c|c|c|c|c|c|c|c|c|c|c|c|}
\hline Umid & PB & $\mathrm{CZ}$ & $\mathrm{N}$ & $\mathrm{P}$ & $\mathrm{P}_{2} \mathrm{O}_{5}$ & $\mathrm{~K}$ & $\mathrm{~K}_{2} \mathrm{O}$ & $\mathrm{Ca}$ & $\mathrm{CaO}$ & $\mathrm{Mg}$ & $\mathrm{MgO}$ & $\mathrm{S}$ & $\mathrm{MO}$ \\
\hline \multicolumn{14}{|c|}{ 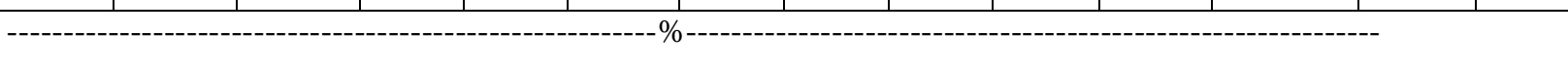 } \\
\hline 0,70 & 6,08 & 15,10 & 0,97 & 0,02 & 0,04 & 0,17 & 0,20 & 0,45 & 0,63 & 0,33 & 0,57 & 0,06 & 14,02 \\
\hline
\end{tabular}

Análises realizadas no Laboratório de Química da Embrapa Algodão. Campina Grande - Pb, 2013.

$\mathrm{PB}=$ proteína bruta; $\mathrm{MO}=$ matéria orgânica.

O plantio da mamona foi realizado em uma área experimental do Campus IV da UEPB, sem proteção ambiental, “a céu aberto”. A reposição de água foi feita manualmente com regadores com objetivo de deixa o solo próximo da capacidade de campo.Foram utilizados o mesmos tratamento do experimento com girassol.

Os tratamentos receberam uma mesma adubação química de acordo com a recomendação da análise do solo (RIBEIRO, 2009), sendo utilizados os seguintes adubos comerciais: sulfato de amônio (21\% de $\mathrm{N})$, superfosfato simples $\left(21 \%\right.$ de $\left.\mathrm{P}_{2} \mathrm{O}_{5}\right)$.

Em cada vaso foram semeadas cinco sementes, deixando uma plantada na época da realização do desbaste aos 15 dias, após a emergência das plântulas. 
O controle de pragas e doenças foi feita organicamente com base na calda de Neem (Azadirachta indica) na proporção de $20 \%$.

O delineamento utilizado foi em blocos casualizado em esquema fatorial $4 \times 2$ referente aos quatro níveis de sulfato de amônia ( $0 ; 30 ; 60 ; 90 \mathrm{~kg} / \mathrm{há})$ e dois tipos de casca de amendoim (natural e moída) em quatro repetições, perfazendo 32 parcelas. As quantidades por tratamento de nitrogênio corresponde a $0,3 \mathrm{~g}$ de N/vaso, $6 \mathrm{~g}$ de $\mathrm{N} / \mathrm{vaso}, 9 \mathrm{~g}$ de N/vaso, respectivamente.

1) $\mathrm{T}_{1}$ - Efeito residual da casca natural $+0 \mathrm{~kg} / \mathrm{ha}$ de $\mathrm{N}+30 \mathrm{~kg} / \mathrm{ha}$ de $\mathrm{P}_{2} \mathrm{O}_{5}$

2) $\mathrm{T}_{2}$. Efeito residual da casca natural $+30 \mathrm{~kg} / \mathrm{ha}$ de $\mathrm{N}+30 \mathrm{~kg} / \mathrm{ha}$ de $\mathrm{P}_{2} \mathrm{O}_{5}$

3) $\mathrm{T}_{3}$-Efeito residual da casca natural $+60 \mathrm{~kg} / \mathrm{ha}$ de $\mathrm{N}+30 \mathrm{~kg} / \mathrm{ha}$ de $\mathrm{P}_{2} \mathrm{O}_{5}$

4) $\mathrm{T}_{4}$ - Efeito residual da casca natural $+90 \mathrm{~kg} / \mathrm{ha}$ de $\mathrm{N}+30 \mathrm{~kg} / \mathrm{ha}$ de $\mathrm{P}_{2} \mathrm{O}_{5}$

5) $\mathrm{T}_{5}$ - Efeito residual da casca moída $+0 \mathrm{~kg} / \mathrm{ha}$ de $\mathrm{N}+30 \mathrm{~kg} / \mathrm{ha}$ de $\mathrm{P}_{2} \mathrm{O}_{5}$

6) $\mathrm{T}_{6}$ - Efeito residual da casca moída $+30 \mathrm{~kg} / \mathrm{ha}$ de $\mathrm{N}+30 \mathrm{~kg} / \mathrm{ha}$ de $\mathrm{P}_{2} \mathrm{O}_{5}$

7) $\mathrm{T}_{7}$ - Efeito residual da casca moída+ $60 \mathrm{~kg} / \mathrm{ha}$ de $\mathrm{N}+30 \mathrm{~kg} / \mathrm{ha}$ de $\mathrm{P}_{2} \mathrm{O}_{5}$

8) $\mathrm{T}_{8}$ - Efeito residual da casca moída+ $90 \mathrm{~kg} / \mathrm{ha}$ de $\mathrm{N}+30 \mathrm{~kg} / \mathrm{ha}$ de $\mathrm{P}_{2} \mathrm{O}_{5}$

No memento da colheitaforam analisadas as seguintes variáveis de crescimento: Altura da planta; diâmetro do caule; numero de folhas; área foliar; número de nós; número de ramificações; comprimento da raiz - Estas variáveis foram analisadas aos 120 dias após o transplante (DAT). Para as variáveis de produção, considerou-se o numero de frutos; número de sementes; número de racemo - Estas variáveis foram analisadas aos 150 DAT.

Paradeterminação da altura da planta, foi utilizada uma fita métrica, graduada em centímetros.Para o diâmetro do caule, foi utilizado um paquímetro digital, aferindo na altura do colo daplanta. A área foliar foi determinada pela soma das áreas de todas as folhas, obtida, através daequação proposta por Severino et al. (2005) que utiliza apenas o comprimento da folha $-\mathrm{S}=0,2622 \times \mathrm{P}^{(2,4248)}$,onde $\mathrm{A}=$ Área Foliar; $\mathrm{L}=$ (length em inglês) Comprimento da nervura principal.

Todos os frutos produzidos pela planta até o último cacho maduro antes do corte foram computados; depois de abertos, procedeu-se à contagem das sementes de cada tratamento. A produção da cultura foi representada pelos seguintes parâmetros: Número de racemo, Número de frutos e Número de sementes.

Os dados obtidos para as níveis de nitrogênio e casca de amendoim foram submetidos à análise de variância mediante significância do teste F. Nas características em que for encontrada significância para o fator quantitativo dos níveis de nitrogênio, foram 
calculados os coeficientes da regressão e o fator qualitativo referentes a casca de amendoim aplicou o teste Tukey (PIMENTEL GOMES,2009).

\section{3 - RESULTADOS E DISCUSSÃO}

De acordo com os resultados observados na ANAVA (quadrado médio), dispostos na tabela 05, observamos a influência das crescentes doses de amônia e a associação da casca de amendoim aplicada à mamoneira. Nota-se diferença estatística pelo teste de $\mathrm{F}$ ao $1 \%$ e 5\% de probabilidade quanto à fonte de variação doses de amônia para as variáveis: diâmetro caulinar e número de ramificações; e de 5\% para a área foliar média. Já os tratamentos referentesà casca atinge efeito significativo a 5\% pelo teste de Tukey para as variáveis: número de folhas e área foliar, tendo ainda interação junto às dosagens de amônia no crescimento da planta, número de folhas e área foliar, apresentando a casca moída, através das médias observadas, melhores resultados na maioria das variáveis analisadas. 
Tabela 4. Resumosda análise de variância referente ao quadrado médio das variáveis de crescimento da mamona Gabriela - Catolé do Rocha, PB 2013.

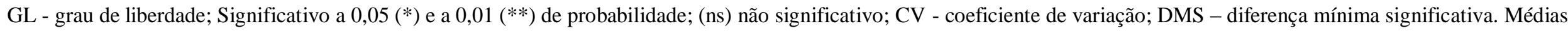

\begin{tabular}{|c|c|c|c|c|c|c|c|c|c|c|c|}
\hline \multirow{2}{*}{$\begin{array}{l}\text { Fonte de } \\
\text { variação }\end{array}$} & \multicolumn{11}{|c|}{ Quadrado Médio } \\
\hline & GL & \multicolumn{2}{|c|}{ Altura da Planta } & $\begin{array}{c}\text { Diâmetro do } \\
\text { Caule }\end{array}$ & $\begin{array}{c}\text { Número de } \\
\text { Ramificações }\end{array}$ & $\begin{array}{c}\text { Número de } \\
\text { Nós }\end{array}$ & \multicolumn{2}{|c|}{ Número de Folhas } & \multicolumn{2}{|c|}{ Área Foliar Média } & $\begin{array}{c}\text { Comprimento } \\
\text { da Raiz }\end{array}$ \\
\hline Bloco & 3 & \multicolumn{2}{|c|}{$71,69^{\mathrm{ns}}$} & $6,44^{\mathrm{ns}}$ & $3,20^{\mathrm{ns}}$ & $43,19^{\mathrm{ns}}$ & \multicolumn{2}{|c|}{$38,86^{\mathrm{ns}}$} & \multicolumn{2}{|c|}{$332792,86^{\mathrm{ns}}$} & $5,41^{\mathrm{ns}}$ \\
\hline Nitrogênio & 3 & \multicolumn{2}{|c|}{$52,28^{\mathrm{ns}}$} & $34,03 * *$ & $32,12 * *$ & $57,78^{\mathrm{ns}}$ & \multicolumn{2}{|c|}{$29,36^{\mathrm{ns}}$} & \multicolumn{2}{|c|}{$506314,69 *$} & $9,25^{\mathrm{ns}}$ \\
\hline Casca & 1 & \multicolumn{2}{|c|}{$1,53^{\mathrm{ns}}$} & $0,03^{\mathrm{ns}}$ & $1,12^{\mathrm{ns}}$ & $7,03^{\mathrm{ns}}$ & \multicolumn{2}{|c|}{$81,28 *$} & \multicolumn{2}{|c|}{$652938,78 *$} & $36,12^{\mathrm{ns}}$ \\
\hline Interação & 3 & \multicolumn{2}{|c|}{$141,78^{*}$} & $1,53^{\mathrm{ns}}$ & $1,45^{\mathrm{ns}}$ & $28,19^{\mathrm{ns}}$ & \multicolumn{2}{|c|}{$18,28^{*}$} & \multicolumn{2}{|c|}{$21772,86^{\mathrm{ns}}$} & $8,70^{\mathrm{ns}}$ \\
\hline Resíduo & 21 & \multicolumn{2}{|c|}{$29,60^{\mathrm{ns}}$} & $1,54^{\mathrm{ns}}$ & $2,54^{\mathrm{ns}}$ & $21,98^{\mathrm{ns}}$ & \multicolumn{2}{|c|}{$13,36^{\mathrm{ns}}$} & \multicolumn{2}{|c|}{$123967,38^{\mathrm{ns}}$} & $11,70^{\mathrm{ns}}$ \\
\hline $\mathrm{CV}(\%)$ & & \multicolumn{2}{|c|}{6,50} & 7,19 & 16,25 & 18,64 & \multicolumn{2}{|c|}{21,78} & \multicolumn{2}{|c|}{23,08} & 9,84 \\
\hline \multicolumn{2}{|l|}{ Nitrogênio } & Natural & Moída & & & & Natural & Moída & Natural & Moída & \\
\hline \multicolumn{2}{|l|}{$\begin{array}{l}\text { Reg. Pol. } \\
\text { Linear }\end{array}$} & $217,80 *$ & $9,11^{\mathrm{ns}}$ & $85,55 * *$ & $93,02 * *$ & - & $10,51^{\mathrm{ns}}$ & $92,45^{*}$ & $166896,45^{*}$ & $549295,51 *$ & - \\
\hline \multicolumn{2}{|l|}{$\begin{array}{l}\text { Reg. Pol. } \\
\text { Quad. }\end{array}$} & $30,25^{\mathrm{ns}}$ & $297,56 * *$ & $16,53^{\mathrm{ns}}$ & $3,12^{\mathrm{ns}}$ & - & $22,56^{\mathrm{ns}}$ & $2,25^{\mathrm{ns}}$ & $247009,00^{* *}$ & $248253,06^{* *}$ & - \\
\hline \multicolumn{2}{|l|}{$\begin{array}{l}\text { Reg. Pol. } \\
\text { Cubica }\end{array}$} & $26,45^{\mathrm{ns}}$ & $1,01^{\mathrm{ns}}$ & $0,00^{\mathrm{ns}}$ & $0,22^{\mathrm{ns}}$ & - & $9,11^{\mathrm{ns}}$ & $6,05^{\mathrm{ns}}$ & $246642,05^{\mathrm{ns}}$ & $26166,61^{\mathrm{ns}}$ & - \\
\hline \multicolumn{2}{|l|}{ Desvio } & 0,00 & 0,00 & 0,00 & 0,00 & - & 0,00 & 0,00 & 0,00 & 0,00 & - \\
\hline \multicolumn{2}{|l|}{ Resíduo } & 29,60 & 29,60 & 1,54 & 2,54 & - & 13,36 & 13,36 & 123967,38 & 123967,38 & - \\
\hline Casca & & \multicolumn{10}{|c|}{ Médias observadas } \\
\hline Natural & & \multicolumn{2}{|c|}{$83,50 \mathrm{a}$} & $17,31 \mathrm{a}$ & $9,62 \mathrm{a}$ & $24,68 \mathrm{a}$ & \multicolumn{2}{|c|}{$15,18 \mathrm{a}$} & \multicolumn{2}{|c|}{$1382,50 \mathrm{a}$} & $33,68 \mathrm{a}$ \\
\hline Moída & & \multicolumn{2}{|c|}{83,93 a } & $17,25 \mathrm{a}$ & $10,00 \mathrm{a}$ & $25,62 \mathrm{a}$ & 18,3 & $7 \mathrm{~b}$ & 1668, & $18 \mathrm{~b}$ & $35,81 \mathrm{a}$ \\
\hline DMS & & & 00 & 0,91 & 1,17 & 3,44 & 2, & & 258 &, 87 & 2,51 \\
\hline
\end{tabular}

seguidasde mesma letra na vertical não diferem entre si $(\mathrm{p}<0,05)$ pelo teste Tukey 


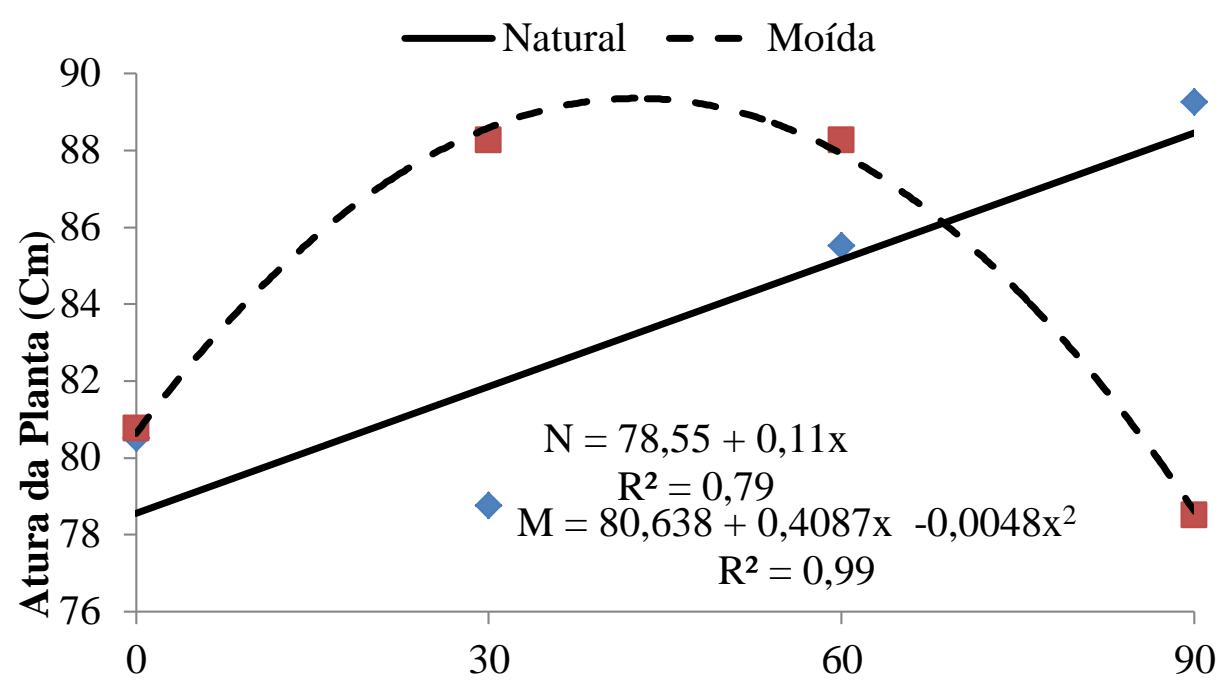

Doses de Amônia (Kg ha-1)

Figura 1. Altura da planta de mamona Gabriela em função da adubação nitrogenada e casca de amendoim natural e moída. UEPB, Catolé do Rocha, 2013.

Na figura 01, são observados os dados referentes a altura da planta cultivada no substratos formado com casca natural de amendoim, onde constatamos um incremento na altura da planta à medida em que se elevou a dosagem de amônia, havendo um incremento $0,11 \mathrm{~cm}$ na altura da planta com aumento unitário da dose de sulfato de amônia. Já nas plantas formada no substratocom casca moída, a altura da planta se ajustou melhor, segundo Silva et al (2011), ao analisarem o desenvolvimento da mamona BRS Energia, alcançando melhor média utilizando casca de mamona moída e a dosagem de $60 \mathrm{~kg} / \mathrm{ha}$ de fertilizante nitrogenado.

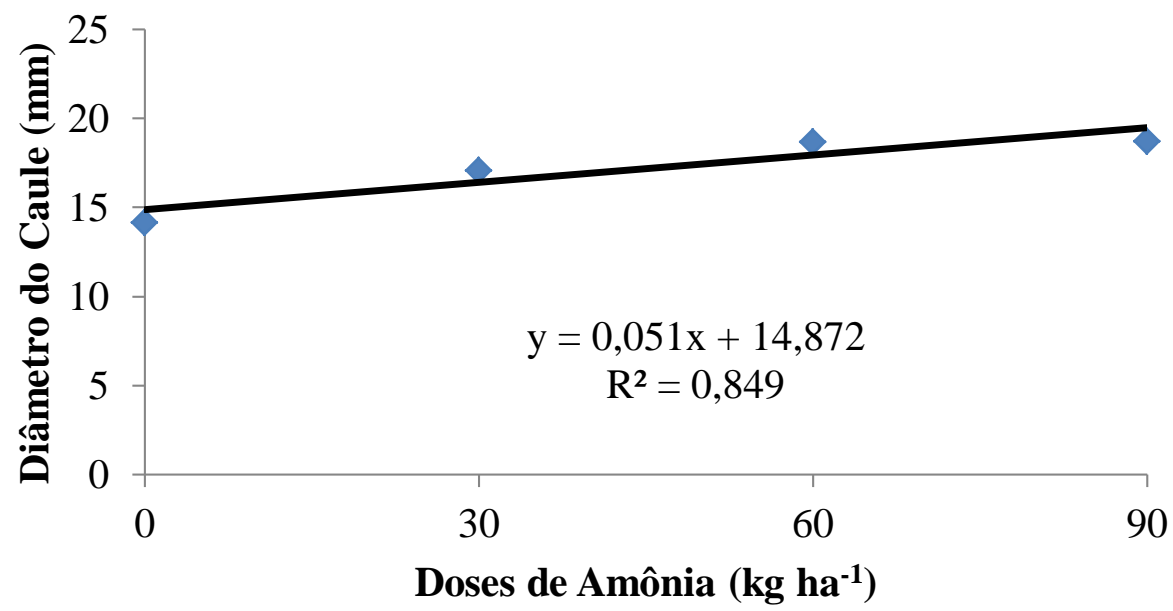

Figura 2. Diâmetro do caule da mamona Gabriela em função da adubação nitrogenada e casca de amendoim natural e moída. UEPB, Catolé do Rocha, 2013. 
Observando a figura 02 temos os dados referentes ao diâmetro do caule em milímetros, o qual apresenta uma regressão com linha de tendência linear crescente, apontando um incremento no diâmetro da planta à medida que se adicionava a amônia, chegando a 18,73 mm com a dosagem de $90 \mathrm{~kg} / \mathrm{ha}$ de amônia, um aumento de cerca de 75,60\% em relação à testemunha, porém, implica que ainda, assim, a dose de $90 \mathrm{~kg} / \mathrm{ha}$ não alcançou $100 \%$ de aproveitamento. Não houve diferença significativa entre as cascas pelo teste de Tukey.

Resultado semelhante foi observado por Oliveira (2013), ao estudar o desenvolvimento do pinhão manso com doses crescentes de ureia e casca de pinhão manso, alcançando melhores resultados com a dosagem de $90 \mathrm{~kg} / \mathrm{ha}$ de ureia no diâmetro do caule.

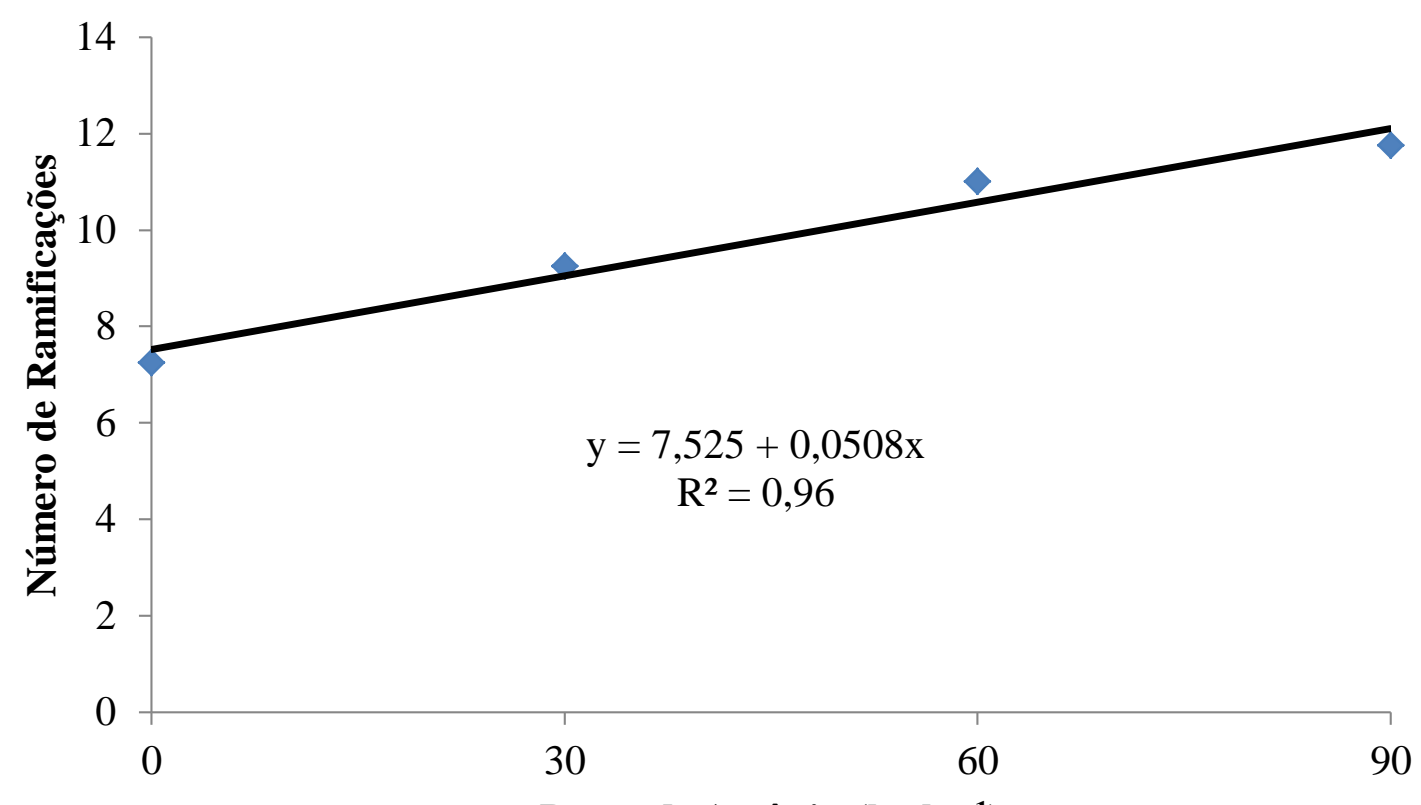

Doses de Amônia (kg ha-1)

Figura 3. Número de Ramificações da mamona Gabriela em função da adubação nitrogenada e casca de amendoim natural e moída. UEPB, Catolé do Rocha, 2013.

Ao analisar a figura 03, constatou-se, com base na equação de regressão, resposta linear crescente com os níveis de adubação nitrogenada aplicada, chegando a alcançar aproximadamente 12 ramificações com a dosagem de $90 \mathrm{~kg} / \mathrm{ha}$, um aumento no numero de ramificações de $61,70 \%$ em relação à testemunha, que alcançou um numero de ramificações inferior a 8 ramificações por planta. Não houve diferença entre as cascas no número de ramificações. 


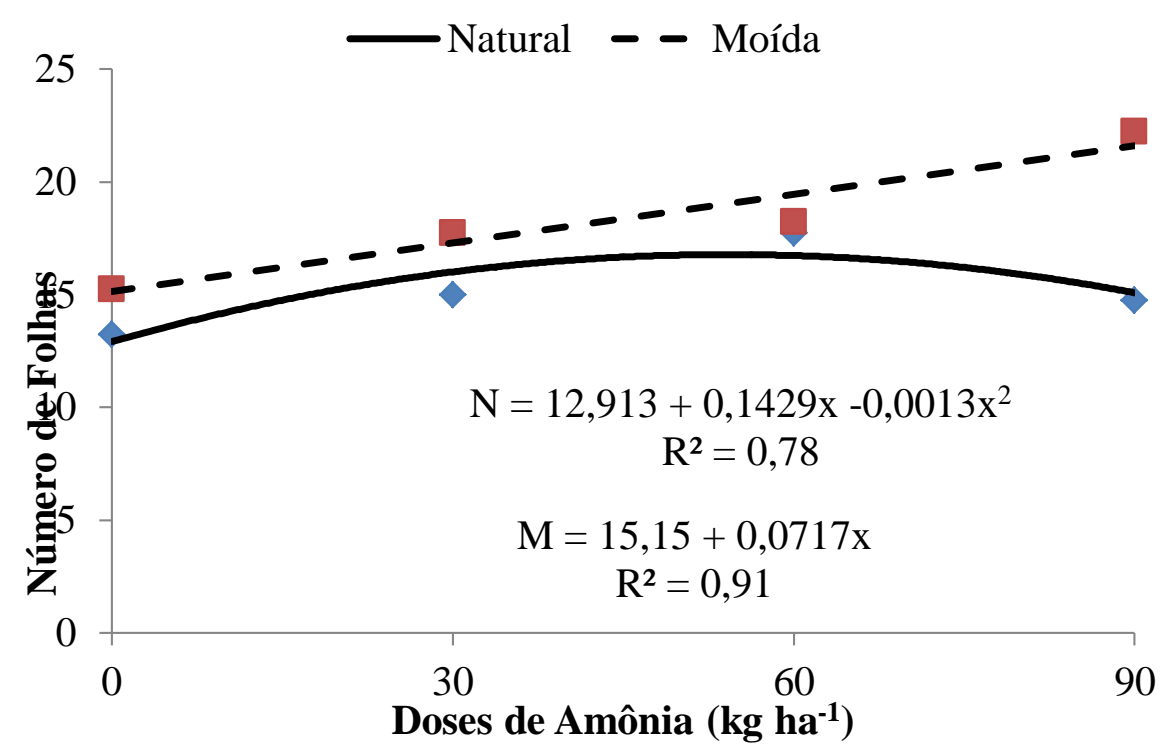

Figura 4. Número de folhas da mamona Gabriela em função da adubação nitrogenada e casca de amendoim natural e moída. UEPB, Catolé do Rocha, 2013.

Oliveira et al. (2010) evidenciam que a adição do adubo orgânico ao solo favorece a disponibilidade dos nutrientes fornecidos pela adubação química. Possivelmente a utilização da casca moída, tornando-se um pó de partículas finas, facilitou a mineralização e disposição de alguns nutrientes para as plantas, caso do nitrogênio, contribuindo para reduzir a relação $\mathrm{C} / \mathrm{N}$ da mesma, mostrando-se mais eficaz do que a casca natural como pode ser observado na figura 04 , onde a casca moída se sobressai à casca natural em todas as dosagens de amônia, apresentando na regressão uma linha de tendência linear que se enquadra às médias observadas, atingindo melhores resultados com a adição de $90 \mathrm{~kg} / \mathrm{ha}$ de amônia, enquanto a casca moída apresentou melhores resultados com a dosagem de $60 \mathrm{~kg} / \mathrm{ha}$ de amônia, entretanto, a casca moída mesmo com a dosagem de $60 \mathrm{~kg} / \mathrm{ha}$ de amônia, mostrou-se superior à casca natural que tem processo de mineralização lento. 


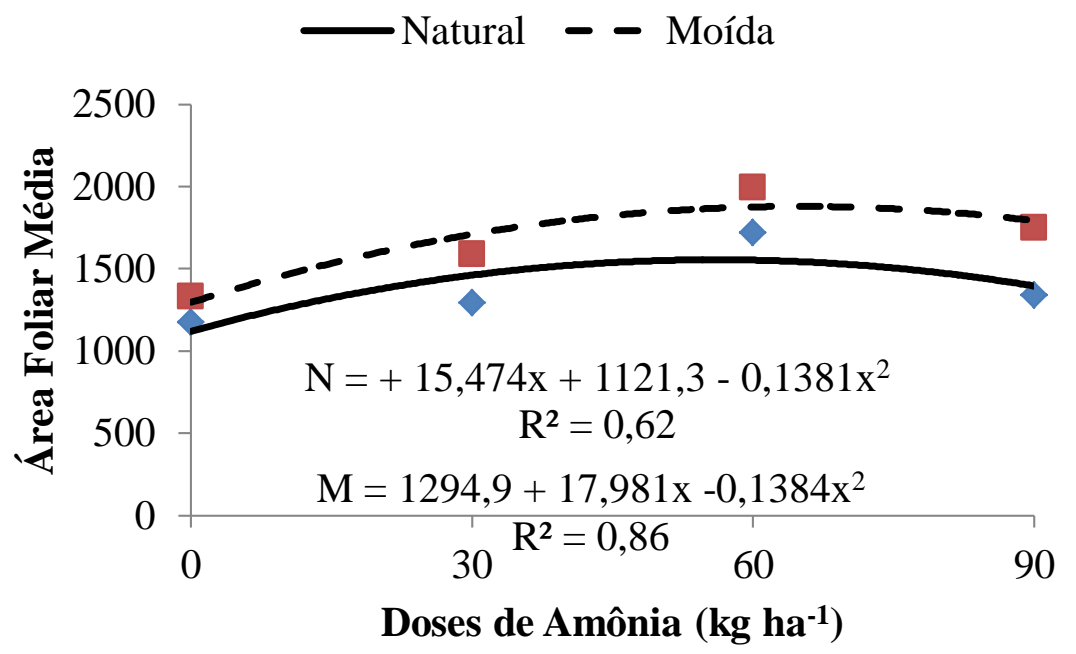

Figura 5. Área Foliar Média da mamona Gabriela em função da adubação nitrogenada e casca de amendoim natural e moída. UEPB, Catolé do Rocha, 2013.

Analisando a Figura 05, observa-se mais uma vez a superioridade da casca de amendoim moída para o desenvolvimento da mamona Gabriela, onde a regressão apresentou uma linha de tendência que se enquadra ao modelo quadrático para ambas as cascas, as quais apresentaram incremento na área foliar da mamoneira à medida em que se aumentava as doses de amônia até a dosagem de $60 \mathrm{~kg} / \mathrm{ha}$, decrescendo em seguida com a dosagem de $90 \mathrm{~kg} / \mathrm{ha}$ de amônia, tendo a dosagem de $60 \mathrm{~kg} / \mathrm{ha}$ um aumento de cerca de 66,90 kg/ha com a casca moída e de aproximadamente $68,41 \%$ com a casca natural em relação à testemunha.

Segundo Lima et al. (2005), a casca de amendoim, apresenta-se como um componente de origem orgânica que quando usado na adubação, favorece a formação de macroporos facilitando, assim a troca gasosa e a distribuição de água em todo o substrato, porém tem decomposição lenta e sua participação no fornecimento de nutrientes é pouco significativa.

Entretanto, a casca moída alcançou médias mais satisfatórias para a área foliar, a qual alcançou 1994,75 $\mathrm{cm}^{2}$, enquanto a casca natural alcançou apenas $1719,03 \mathrm{~cm}^{2}$ com a dosagem de 60 $\mathrm{kg} / \mathrm{ha}$, o que implica num incremento de aproximadamente $86 \%$ da casca moída sobre a casca natural. Esses resultados divergem dos obtidos por Silva et al. (2011), que não obtiveram diferença estatística entre as cascas ao analisarem o desenvolvimento da mamona BRS energia sob efeito da combinação da casca de mamona e fertilizantes químicos, alcançando ainda melhores resultados apenas com a dosagem de $90 \mathrm{~kg} / \mathrm{ha}$.

Na Tabela 05, temos a ANAVA (quadrado médios) dos dados referentes à produção da mamoneira. Observa-se diferença significativa para as cascas pelo teste de Tukey a $1 \%$ de 
probabilidade na variável número de racemos, e efeito significativo das doses a $1 \%$ pelo teste de Tukey nas variáveis número de frutos e número de sementes.

Ainda é possível constatar, através das médias observadas nas diferentes cascas que a casca moída se sobressai à casca natural, mesmo quando não há diferença estatística entre elas. Silva et al. (2011) afirmam que um material orgânico que seja aplicado ao solo, dificilmente terá todos os nutrientes e quantidades essenciais destes para o desenvolvimento pleno da planta, o que limita o uso exclusivo da adubação orgânica como fonte de nutrientes, sendo necessário, assim uma complementação com a adubação mineral. 
Tabela 5. Resumos da análise de variância referente ao quadrado médio das variáveis de produção - UEPB, Catolé do Rocha, PB - 2013. GL - grau de liberdade.

\begin{tabular}{|c|c|c|c|c|c|}
\hline \multirow{2}{*}{ Fonte de variação } & \multicolumn{3}{|c|}{$\begin{array}{l}\text { Quadrado Médio } \\
\text { Variáveis de Produção }\end{array}$} & \multirow[b]{2}{*}{ Número de Frutos } & \multirow[b]{2}{*}{ Número de Sementes } \\
\hline & GL & Núm & cemos & & \\
\hline Bloco & 3 & \multicolumn{2}{|c|}{$0,44^{\mathrm{ns}}$} & $1,12^{\mathrm{ns}}$ & $12,61^{\mathrm{ns}}$ \\
\hline Nitrogênio & 3 & \multicolumn{2}{|c|}{$0,36^{\text {ns }}$} & $543,45^{* *}$ & $4847,19 * *$ \\
\hline Casca & 1 & \multicolumn{2}{|c|}{$3,78 * *$} & $1,12^{\mathrm{ns}}$ & $9,03^{\mathrm{ns}}$ \\
\hline Interação & 3 & \multicolumn{2}{|c|}{$0,61^{* *}$} & $28,45^{\mathrm{ns}}$ & $243,86^{\mathrm{ns}}$ \\
\hline Resíduo & 21 & \multicolumn{2}{|c|}{$0,51^{\mathrm{ns}}$} & $20,12^{\mathrm{ns}}$ & $178,54^{\mathrm{ns}}$ \\
\hline $\mathrm{CV}(\%)$ & & \multicolumn{2}{|c|}{18,16} & 15,84 & 15,68 \\
\hline Nitrogênio & & Natural & Moída & & \\
\hline \multicolumn{6}{|l|}{ Reg. Pol. Linear } \\
\hline Reg. Pol. Quad. & 1 & $0,00^{\mathrm{ns}}$ & $1,56^{\mathrm{ns}}$ & $45,12^{\mathrm{ns}}$ & $385,03^{\mathrm{ns}}$ \\
\hline Reg. Pol. Cubica & 1 & $0,45^{\mathrm{ns}}$ & $0,01^{\mathrm{ns}}$ & $60,02^{\mathrm{ns}}$ & $522,00^{\mathrm{ns}}$ \\
\hline Desvio & 0 & 0,00 & 0,00 & 0,00 & 0,00 \\
\hline Resíduo & 21 & 0,51 & 0,51 & 20,12 & 178,54 \\
\hline Casca & & & & Médias observadas & \\
\hline Natural & & & & $28,12 \mathrm{a}$ & $84,68 \mathrm{a}$ \\
\hline Moída & & & & $28,50 \mathrm{a}$ & $85,75 \mathrm{a}$ \\
\hline DMS & & & & 3,29 & 3,34 \\
\hline
\end{tabular}

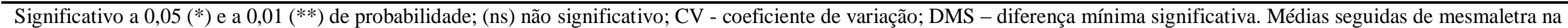
vertical não diferem entre si $(\mathrm{p}<0,05)$ pelo teste Tukey 


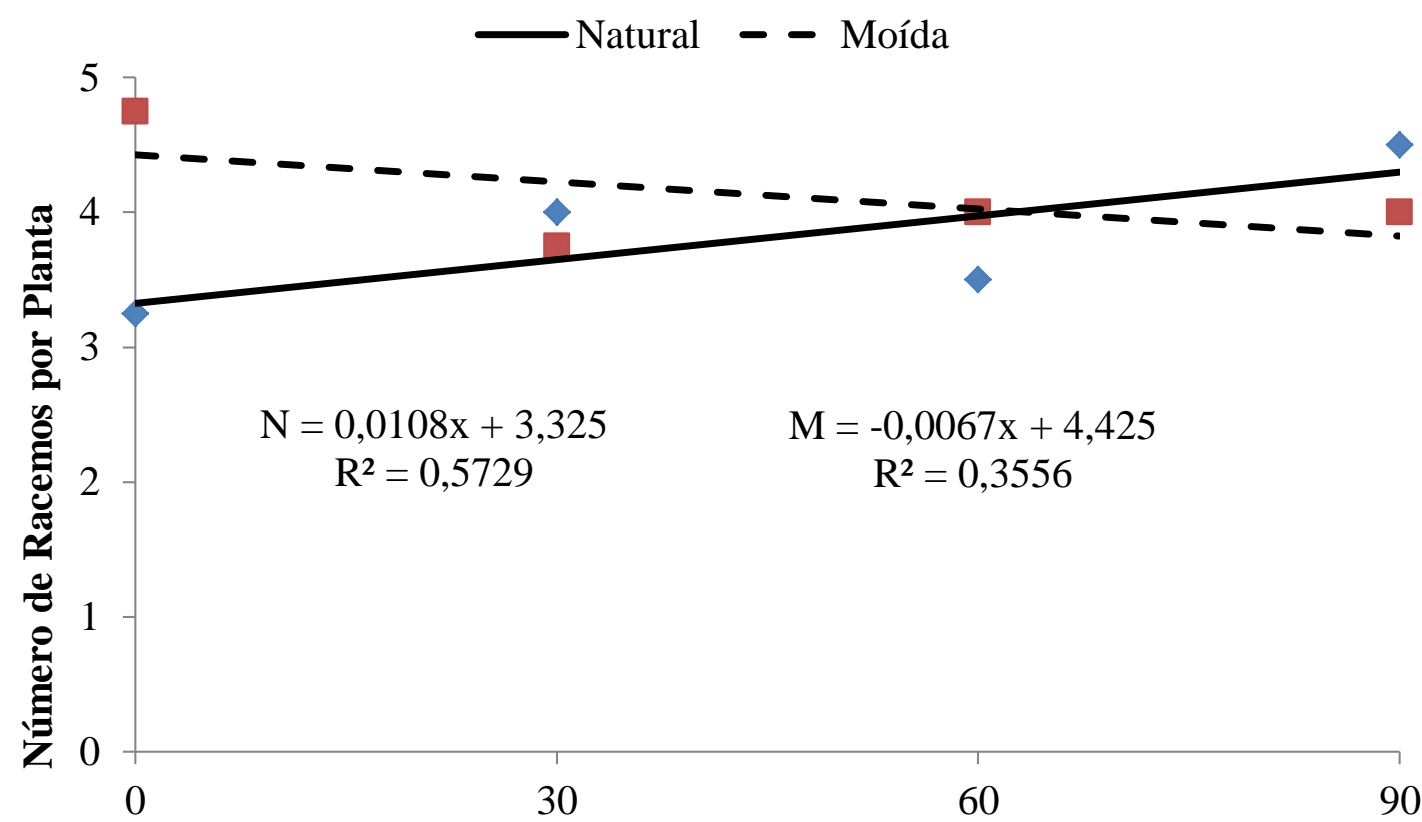

Doses de Amônia (kg ha'-1)

Figura 6. Número de Racemos da mamona Gabriela em função da adubação nitrogenada e casca de amendoim natural e moída. UEPB, Catolé do Rocha, 2013.

Como se pode observar na figura 06, a regressão mostrou uma linha de tendência linear para as cascas utilizadas, sendo crescente para a casca natural e decrescente par a casca moída, as quais intercedem na dosagem de $60 \mathrm{~kg} / \mathrm{ha}$ de amônia. Ao utilizarmos a dosagem de $90 \mathrm{~kg} / \mathrm{ha}$ de amônia, obtivemos resultados mais satisfatórios com a casca natural, diferindo do que vimos nas variáveis de crescimento onde a casca moída se sobressaia em todas as dosagens. 


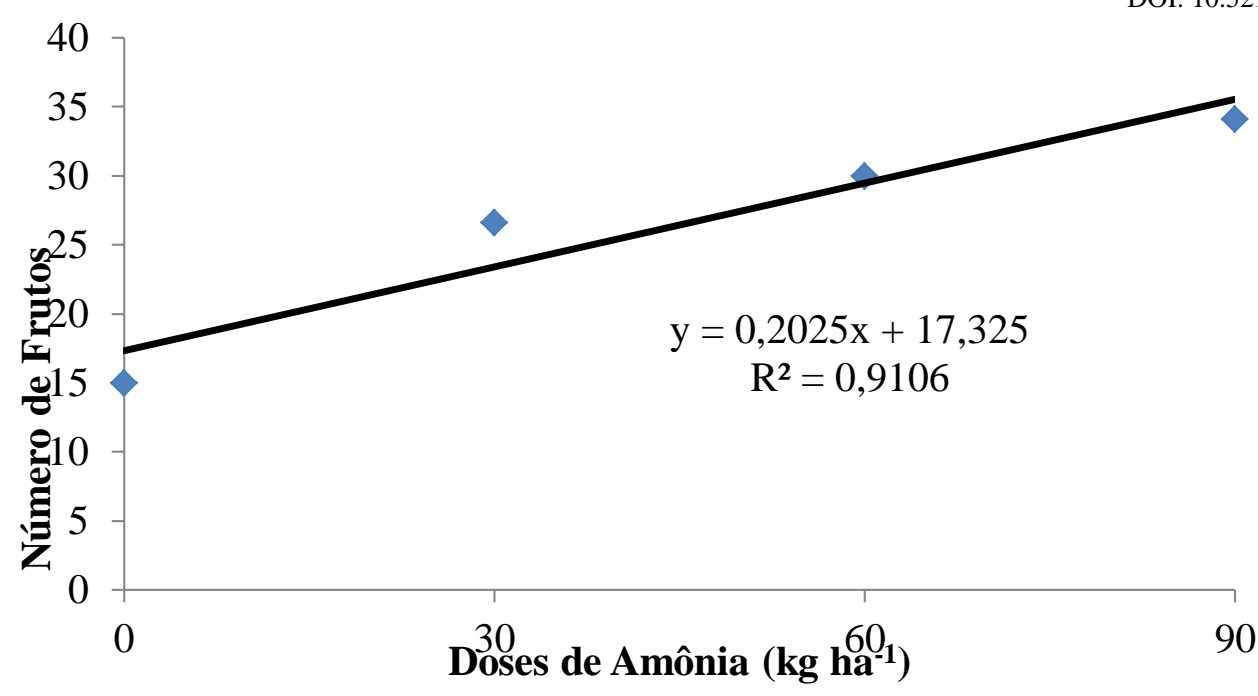

Figura 7. Número de frutos da mamona Gabriela em função da adubação nitrogenada e casca de amendoim natural e moída. UEPB, Catolé do Rocha, 2013.

Na figura 07, são visualizadas a regressão para a fator doses de sulfato de amônia, verificando-se aumento linear no número de frutos, á medida em que se elevaram as doses de sulfato de amônia com aumento de 0,2025 por aumento unitário das doses de sulfato de amônia, alcançando valor máximo de 35,5 frutos ( planta $^{-1}$ ). O que se pode evidenciar, neste experimento que a planta responde positivamente as doses superior a $90 \mathrm{~kg} / \mathrm{N}$.

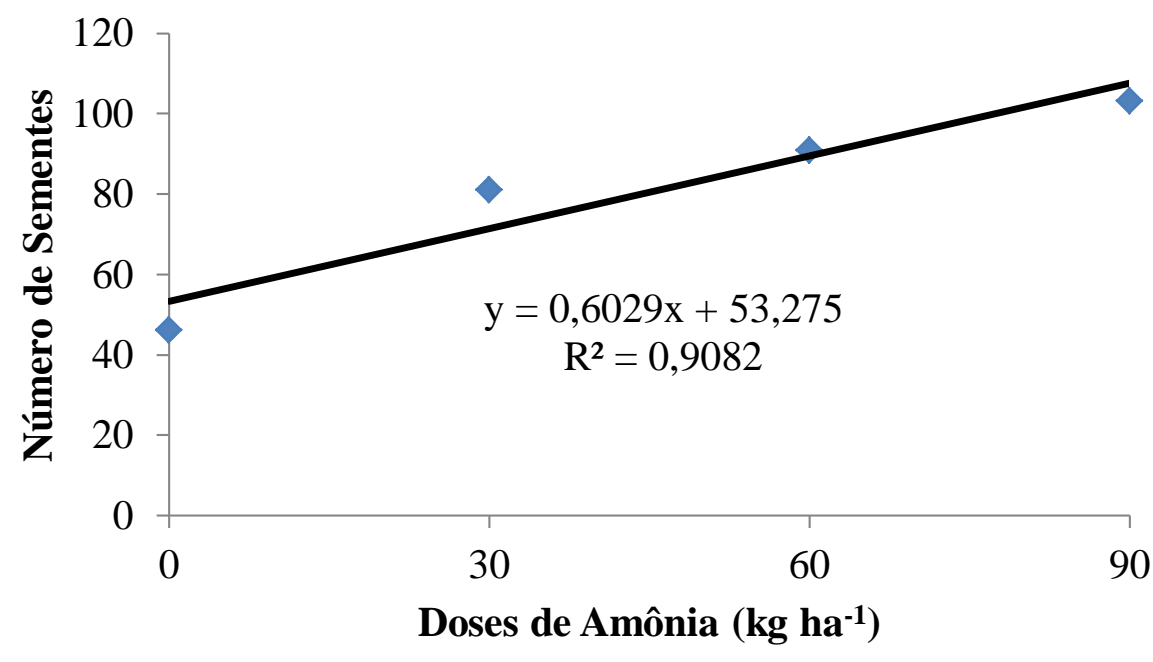

Figura 8. Número de sementes da mamona Gabriela em função da adubação nitrogenada e casca de amendoim natural e moída. UEPB, Catolé do Rocha, 2013.

Na Figura 08, quando do número de sementes, a análise de variância indicou efeito significativo das doses de sulfato de amônia em cobertura. Nota-se que a aplicação de sulfato de amônia em cobertura resultou em um efeito linear, com o aumento do número de sementes a medida que se elevou as dose de sulfato de amônia, chegando ao número máximo de 107,5sementes 
(planta ${ }^{1}$ ). Isso significa que a adubação nitrogenada é muito importante para a cultura da mamoneira, fato confirmado por Mesquita et al. (2011) que observaram maior produção da mamoneira com aumento da dose de nitrogênio.

\section{4 - CONCLUSÕES}

2 - Em geral, a utilização da casca moída no substrato sobressaiua casca natural no desenvolvimento da mamoneira.

3 - A mamoneira responde positivamente a doses superiores a $90 \mathrm{~kg} / \mathrm{ha}$ de nitrogênio.

4 - A casca moída de amendoim apresentou melhor desempenho quanto ao crescimento e produção em comparação a casca natural.

\section{5 - REFERÊNCIAS}

BAHIA, H.F, SILVA S. A., FERNANDEZ L. G., LEDO C. A. DA S. E MOREIRA R. F. C. Divergência genética entre cinco cultivares de mamoneira. Pesquisa Agropecuária Brasileira, Brasília, v.43, n.3, p.357-362, mar. 2008.

BELTRÃO, N. E. M.; FILHO, J. F..Estimativa da respiração de uma comunidade de plantas, via valores primários (área foliar e fitomassa). Campina Grande: Embrapa - CNPA, 2008. 12 p. (Embrapa - CNPA. Circular Técnica, 122).

CARVALHO, L. O. de. Cultura da mamoneira. Campinas: CATI, 2008. p.3. (CATI) Comunicado técnico, 73).

COSTA, F. X.; BELTRÃO, N. E. de M.; SIlVA, F. E. A.; MElO FILHO, J. S.; SILVA. M. A. Disponibilidade de nutrientes no solo em função de doses de matéria orgânica no plantio da mamona. Revista verde de agroecologia e desenvolvimento sustentável.Mossoró - RN, v.5, n.3, p. $204-212$, julho/setembro de 2010 b.

COSTA, F. X.; BELTRÃO, N. E. M.; LIMA, V. L. A. de; NUNES JUNIOR, E. S; GUIMARÃES, M. M. B.; DAMACENO, F. A. V. Efeito do lixo orgânico e torta de mamona nas características de crescimento da mamoneira(RicinuscommunisL.). Revista Engenharia Ambiental: pesquisa e tecnologia - Espírito Santo do Pinhal, v. 6, n. 1, p. 259-268, jan/abr 2009.

COSTA, F. X.; NUNES JUNIOR, E. S; MELO FILHO, J. S. Efeito da torta de mamona no plantio da mamoneira com diferente densidade global do solo. Revista Engenharia Ambiental: pesquisa e tecnologia - Espírito Santo do Pinhal - SP, v. 7, n. 1, p. 229-238, jan. /mar .2010a.

COSTA, F. X.; BELTRÃO, N. E. M.; MELO FILHO, J. S.; SILVA, D. P.; DANTAS, G. F.; SILVA, F. E. A. Avaliação da fisiologia e bioquímica da mamoneira em função da aplicação de composto orgânico de lixo e torta de mamona como fertilizantes. Revista Engenharia Ambiental: pesquisa e tecnologia, Espírito Santo do Pinhal, v. 8, n. 1, p. 101 - 109, 2011. 
LIMA, R. L. S.; SEVERINO, L. S.; ALBUQUERQUE, R. C.; BELTRÃO, N. E. M.; SAMPAIO, L. R. Casca e torta de mamona avaliados em vasos como fertilizantes orgânicos. Revista Caatinga, Mossoró, v.21, n.5, p.102 - 106, 2008.

LIMA, R. L. S.; SEVERINO, L. S.; FERREIRA, G. B.; SOFIATTI, G. B. F; SAMPAIO, L. R.; BELTRÃO, N. E. M. de. Casca de mamona associada a quatro fontes de matéria orgânica para a produção de mudas de pinhão-manso. Revista Ceres, v.58, p.232-237, 2011.

MESQUITA, E. F.; CHAVES, L.G.C.; GUERRA, H.O.C. Fitomassa e componentes da produção da mamona fertilizada com nitrogênio, fósforo e potássio. Revista Agrarian, v.4. n. 14, p. $344-$ $351,2011$.

OLIVEIRA, A. E. S.; SÁ, J. R.; MEDEIROS, J. F.; NOGUEIRA, N. W.; SILVA, K. J. P. Interação da adubação organo-mineral no estado nutricional das plantas. Revista Verde de Agroecologia e Desenvolvimento Sustentável, v.5, p.53-58, 2010.

OLIVEIRA, D. F. S.; Crescimento e produção de pinhão manso em função da fertilização nitrogenada e adição de resíduos sólidos orgânicos [Monografia] - Universidade Estadual da Paraíba - Catolé do Rocha, PB, 2013.

PIMENTEL GOMES, F. Curso de estatística experimental. Piracicaba: FEALQ, p. 541, 2009.

RIBEIRO, S. et al. Resposta da mamoneira cultivar BRS-188 Paraguaçu à aplicação de nitrogênio, fósforo e potássio. Revista Ciência Agronômica, v. 40, n. 4, p. 465-473, 2009.

SEVERINO, Liv Soares; CARDOSO, GleibsonDionízio; VALE, Leandro Silva; SANTOS, José Wellington dos. Método para Determinação da Área Foliar da Mamoneira. Campina Grande, PB, 2005.

SILVA, M. A.; SILVA, F. E. A.; NUNES JUNIOR, E. S.; COSTA,F. X.; MELO FILHO, J. S.; Combinação de casca de mamona e fertilizantes químicos na adubação da mamoneira BRS Energia.

Revista Trópica - Ciências Agrárias e Biológicas V. 5, N. 1, p. 48, 2011. 